\begin{tabular}{|c|c|}
\hline PORT SAID ENGINEERING RESEARCH JOURNAL \\
Faculty of Engineering - Port Said University \\
Volume 21 No. 1 March 2017 pp. 1:7
\end{tabular}

\title{
Mixed Mode buildings as approach to reduce energy consumption in office buildings in greater Cairo in Egypt
}

Nancy M. Badawy ${ }^{1}$, Ahmed R. Abdin ${ }^{2}$, Abbas M. El-zafarany ${ }^{3}$

\begin{abstract}
Passive buildings conserve energy by decreasing need for HVAC, but it is hard to achieve full thermal comfort unlike air-conditioned buildings. mixed-mode buildings depend on passive mode when thermal comfort is achievable with natural ventilation and switch to active mode otherwise, it can give the building the best of both worlds.

Mixed Mode building is a combine of natural ventilated building and AC building which needs different strategy of design which make the Mixed Mode building face a problem in design. this paper aims to reach a strategy to design mixed mode buildings envelope in greater Cairo to reach optimum energy consumption. the research concludes that the MMB is near to be a natural ventilated building with slight heavier south envelope which reach $0.8 \mathrm{w} / \mathrm{m} 2 . \mathrm{k}$ and $20 \%$ WWR although the north façade still a light skin with $2 \mathrm{w} / \mathrm{m} 2 \mathrm{k}$ and $50 \% \mathrm{WWR}$.
\end{abstract}

\section{INTRODUCTION}

\subsection{Definition of Mixed Mode buildings}

Mixed mode system is a principle that gain the advantage of natural ventilation NV, Air condition AC systems to reach comfort and to minimized energy consumptions there are a lot of definitions of mixed mode systems (MM buildings) from different researchers and institutes. "It is a building in which occupants can open windows, and which is designed with effective passive strategies for limiting the effects of the external climate. The passively designed building is utilized to provide acceptable conditions for the majority of the year, and is supplemented by a mechanical system, either on an 'as and when required' basis, or on a seasonal basis"

"Mixed-mode refers to a hybrid approach to space conditioning that uses a combination of natural ventilation from operable windows (either manually or automatically controlled), and mechanical systems that include air distribution equipment and refrigeration

equipment for cooling. A well-designed mixed-mode building begins with intelligent facade design to minimize cooling loads.

${ }^{I}$ Architecture and Urban Planning Department, Faculty of

Engineering, Port Said University, Port Said, Egypt, Email: nancybadawy2012@gmail.com

2 Architecture and Urban Planning Department, Faculty of

Engineering, Cairo University, Cairo, Egypt, Email:

aabdin2010@gmail.com

3 Faculty of Urban and Regional Planning, Cairo University,

Cairo, Egypt, Email:

zafarany@hotmail.com
It then integrates the use of air-conditioning when and where it is necessary, with the use of natural ventilation whenever it is feasible or desirable, to maximize comfort while avoiding the significant energy use and operating costs of year-round air conditioning."

This research aims to define the mixed mode buildings as "MM buildings is an approach to design office buildings in hot arid climate as a passive building with operable windows which rely on natural ventilation as possible using the passive influence of air velocity to expand the comfort range of natural ventilation even if outdoor conditions are out of comfort and switch to AC systems when occupants can't adapt to indoor conditions in the same place at different time to optimum energy consumption."

Mixed mode system is used to maximize advantages of passive system and minimized active systems in buildings in a mixed strategy, throughout different time of the year with reductions in pollution, greenhouse gas emissions and energy consumption.

Office buildings in Cairo Egypt have a big internal load which needs applications to get rid of high internal loads by convection (ventilation and fan assistance), conduction (thermal mass and phase change) and radiation (radiant cooling, heat pipes and labyrinth).

The research focus on convection applications to be the reason of heat loss.

\subsection{Types of mixed mode buildings}

All researches about mixed mode buildings classified mixed mode buildings according to type of operation. The research classified the MMB types according to type of switching between natural ventilation and $\mathrm{AC}$ which affects the energy consumption in buildings. mixed mode building need to determine the time to switch between nature ventilation and 
$\mathrm{AC}$, in order to reach optimum design reaching comfort with minimum energy consumption and required air quality .so determine comfort indices used in both uniform and non-uniform condition have a big importance in indicating operating schedule of MMB. International MMB types divides on three methodologiesi

- Concurrent mixed mode operation (same space, same time)

- Change over design (Different spaces, same time)

Zone system (Same space, different times)

The research approach classified MMB types into three types

- Smart MM buildings.

- pre-designed scheduled MMB.

- manual adaptive MMB.

the research focus on the choose change over type and manual adaptive $\mathrm{MMB}$ as it the most spread type in Egypt, and compare it with other types, It should be noted that most MMB are not fully automated, and occupants are usually responsible for operating operable windows in office spaces. This "adaptive" approach relay on comfort indices.

\subsubsection{International MMB types}

\subsubsection{Concurrent (Same space, same time)}

Concurrent mixed-mode operation is the most prevalent design strategy in practice today, in which the airconditioning system and operable windows operate in the same space and at the same time. The HVAC system may serve as supplemental or "background" ventilation and cooling while occupants are free to open windows based on individual preference. Typical examples include open-plan office space with standard VAV airconditioning systems and operable windows, where perhaps perimeter VAV zones may go to minimum air when sensor indicates that a window has been opened.

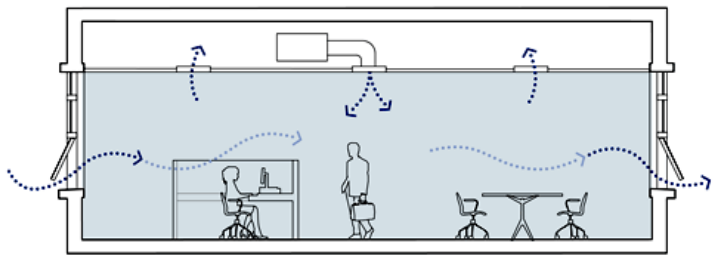

Figure 1 Concurrent mixed mode type [Source: CBE Indoor Environmental Quality, 2012

\subsubsection{Change-over (Same space, different times)}

Change-over designs are becoming increasingly common, where the building "changes-over" between natural ventilation and air-conditioning on a seasonal or even daily basis. The building automation system may determine the mode of operating based on outdoor temperature, an occupancy sensor, a window (open or closed) sensor, or based on operator commands. Typical examples include individual offices with operable windows and personal air conditioning units that shut down for a given office anytime a sensor indicates that a window has been opened; or a building envelope where automatic louvers open to provide natural ventilation when the HVAC system is in economizer mode, and then close when the system is in cooling or heating mode.

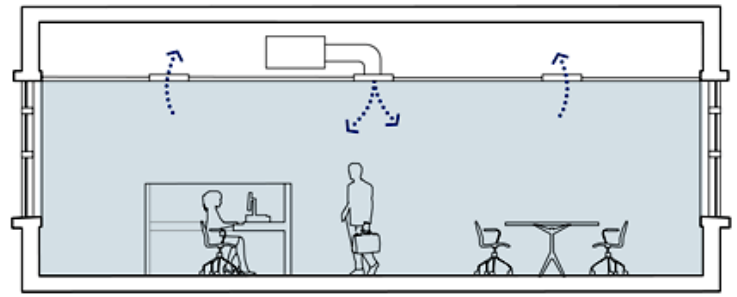

Figure2 changeover mixed mode type [Source: CBE Indoor Environmental Quality, 2012

\subsubsection{Zoned (Different spaces, same time)}

Zoned systems are also common, where different zones within the building have different conditioning strategies. Typical examples include naturally ventilated office buildings with operable windows and a ducted heating/ventilation system, or supplemental mechanical cooling provided only to conference rooms. For many mixed-mode buildings, operating conditions sometimes deviate somewhat from their original design intent (e.g., a building originally designed for seasonal changeover between air-conditioning and natural ventilation may, in practice, operate both systems concurrently).

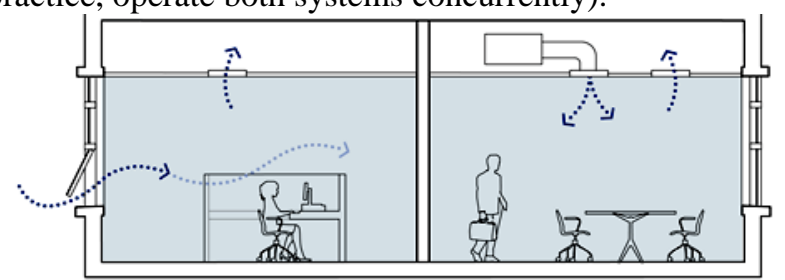

Figure 3 zoned mixed mode type

[Source: CBE Indoor Environmental Quality, 2012 


\subsubsection{Research MMB types}

\subsubsection{Smart MM buildings.}

The building is controlled with the aid of digital/mechanical system depends on detectors and sensors, when the space is being used by assembly or when exterior conditions prohibit the exclusive use of natural ventilation. It can be cooled with the displacement system supplied through the floor. The system also provides adequate fresh air for high occupancy levels and is controlled with occupancy sensors.

\subsubsection{2. pre-designed scheduled MMB.}

This category is manual controlled with a pre-design which recommend hourly, daily or seasonal switching schedule which may be manually or alarmed recommended.

It may be automatic control with sensors or pre-designed seasonal schedule.

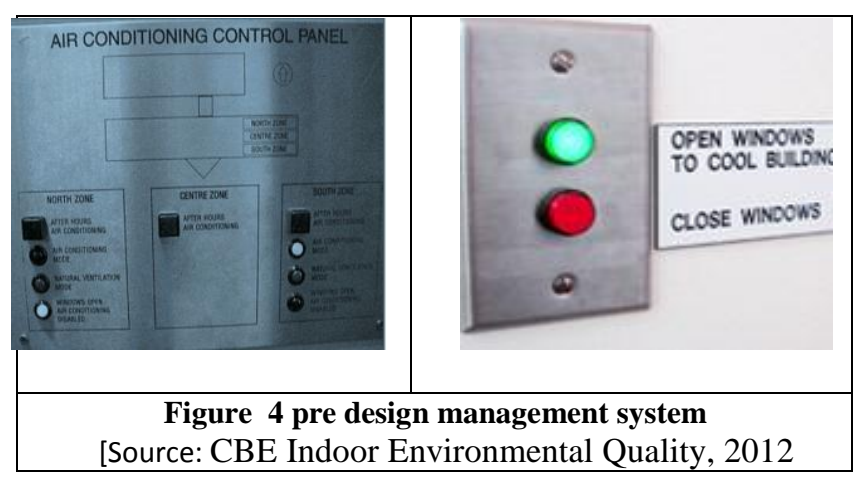

\subsubsection{3. manual adaptive MMB.}

Most Egyptian buildings is manual adaptive MM buildings which rely on occupants' sensation on switching manually between modes.

Occupants did not have any recommendation except their adaptation to outdoor conditions So most buildings rely on natural ventilation in outdoor comfort hours only.

This type may consume more energy especially in hot arid zone by open natural ventilation in very high temperature which leads to increase energy consumption.

\subsection{MMB operating strategy}

Manual adaptive MMB is the most spread type of MMB in Egypt which may be Depend on people behavior and respond to conditions depending on occupant satisfaction and adaptation behavior to context conditions and building operative temperature, the effect of natural ventilation on thermal comfort indices (PMV, SET, thermal adaptation model) in uniform and non-uniform condition and determine comfort hours and when we go out of comfort to switch between natural and mechanical ventilation.

A previous research on MMB schedule in greater Cairo determine an operating schedule to switch between natural ventilation and $\mathrm{AC}$ based on air velocity

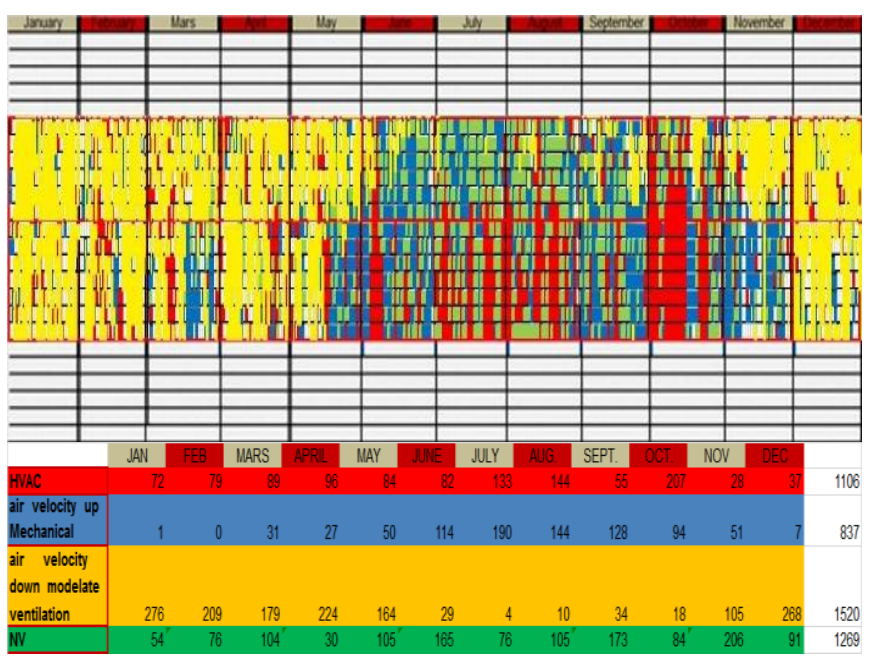

\section{Figure 5 MMB schedule}

[Source: researcher]

The schedule represents the hours which can rely on natural ventilation, the hours which needs to decrease or increase air velocity to reach comfort and hours which must rely on $\mathrm{AC}$.

\section{RESEARCH PROBLEM}

MMB faced a design problem to combine passive and active strategies to reach optimum design as there are some passive techniques in natural ventilated buildings which harm AC buildings such as open high plans and high WWR. on the other hand, there are some techniques in AC may harm natural ventilated buildings such as inner insulation which make a design strategy to MMB which spread over greater Cairo is a must.

\section{METHOD}

The research used the simulation program of DesignBuilder to compare energy consumption and comfort hours in typical office building in Cairo.

The research tries to examine envelope parameters in MMB (WWR and U-factor) and building height 


\subsection{Simulation model}

The base case configuration used in this study by using the model with the default thermal mass with $20 \%$ opening with brick, insulation, plaster with $0.45 \mathrm{w} / \mathrm{m} 2 \mathrm{k}$ for $\mathrm{u}$-factor we will increase thermal mass to examine external north wall u-factors $(0.45,0.8,1.2)$ and investigate WWR (10\%-20\%-30\%)

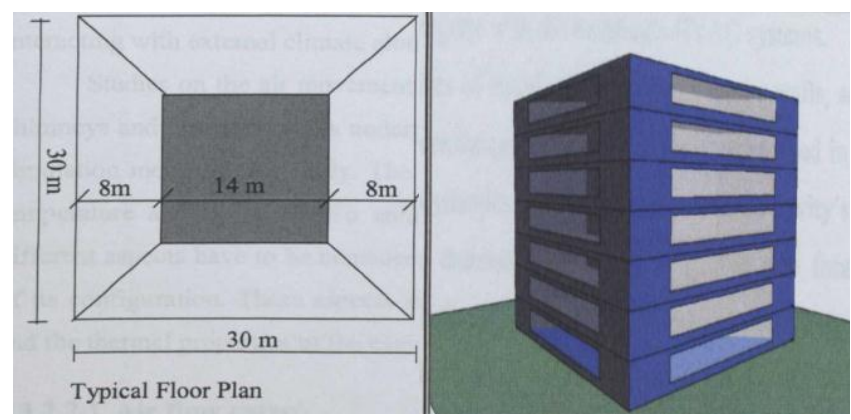

Figure 6 Building base case (source :researcher)

\subsection{Comfort parameters}

There is a difference between the influence of air speed on thermal comfort in uniform and non-uniform conditions, from Olygay bioclimatic chart (Olgyay, 1963)ii (fig. 3) which explained the effect of air speed on comfort to Marqus and Morris charts which explained the rise of temperature comfort range with raise of air velocity (Marqus and Morris, 1960.)(fig.4).iii

Givoni discussed the influence of increased air velocity in comfort in a passive model in hot and humid climates with raise of temperature (Givoni, 1992.)iv. Also, ASHRAE standard 55 shows that increased air speed may be used to offset an increase in the operative temperature (fig.5), but not by more than $3.0^{\circ} \mathrm{C}\left(5.4^{\circ} \mathrm{F}\right)$ (ANSI/ASHRAE Addenda d, 2004). The elevated air speed must be under the direct control of the affected occupants and adjustable in steps no greater than 0.15 $\mathrm{m} / \mathrm{s}$ (30 fpm) .on the other hand the HVAC engineers usually considered increased air velocity as a design mistake it is called draft which is one of four factors of discomfort (Ken Loudermilk, 2009)v (Radiant temperature asymmetry, Draft, Vertical air temperature difference and Floor surface temperature) (ANSI/ASHRAE Addenda d, 2004) so the research put SET and adaptive model as the comfort method when comparing between cases as a constrain in the building

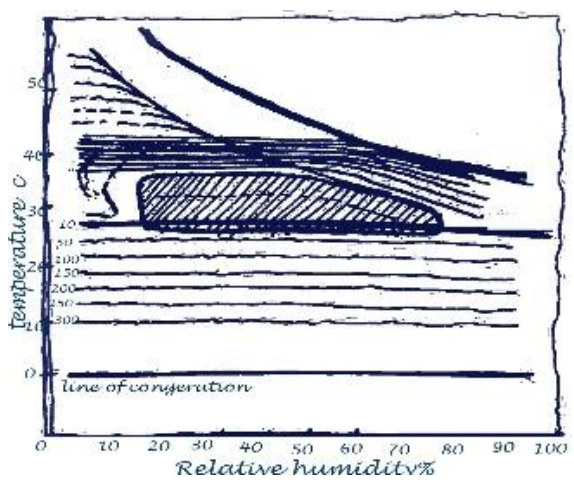

Figure 7 bioclimatic chart based on Olygay (Olgyay, 1963)

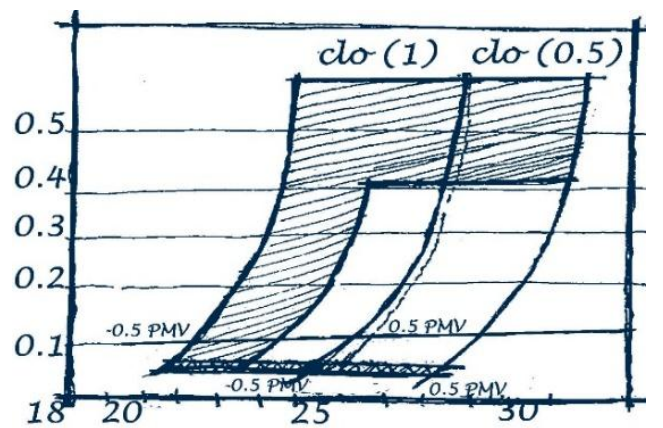

Figure 8 influence of air speed and temperature on comfort based on ASHRAE 55-2010

1 Table base case conditions

\begin{tabular}{|l|l|}
\hline Construction & Element \\
\hline Screed ,concrete, carpet & floor \\
\hline Screed, concrete. & ceiling \\
\hline $\begin{array}{c}\text { Brick, insulation, block, } \\
\text { plaster }\end{array}$ & External wall \\
\hline $\mathbf{0 . 3 p e o p l e / m 2}$ & occupancy \\
\hline $\mathbf{1 8}$ & Heating set point \\
\hline $\mathbf{2 6}$ & \begin{tabular}{l} 
Cooling set point \\
Schedule working \\
\hline $\mathbf{9}$ AM- 6PM \\
hours
\end{tabular} \\
\hline
\end{tabular}

\subsection{Simulation method}

Design builder program is a reputable environmental simulation program Provide detailed design data on airflow ,temperature,energy consumption and energy consumption in and around buildings using the same energyplus and general purpose CFD packages, but at a fraction of the cost and without the need for specialist knowledge.

\section{RESULTS AND DISCUSSIONS 4.1.U-factor analysis of north façade}


by examine different u-factor $(0.15,0.45,0.8,1.2,2)$ $\mathrm{w} / \mathrm{m}^{2} . \mathrm{k}$ to north façade results an energy consumption distributions differ according to $\mathrm{u}$ factor

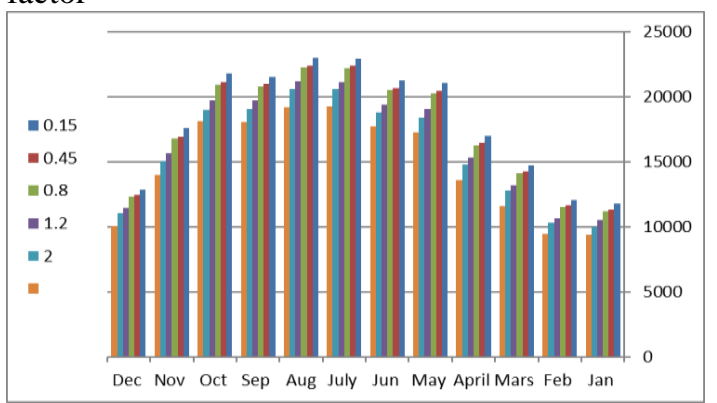

Figure 9 monthly energy consumption on north façade with different $u$-factor

(source: researcher)

From the previous chart, it is clear that in all months that the massive envelope of $\mathrm{u}$-factor 0.15 $\mathrm{w} / \mathrm{m}^{2} . \mathrm{k}$ meets the highest energy consumption which harms the natural ventilations hours and the light skin of u-factor $2 \mathrm{w} / \mathrm{m}^{2} . \mathrm{k}$ meets the $\mathrm{min}$. energy consumption while it nearly be constant with u-factor $0.45-0.8 \mathrm{w} / \mathrm{m}^{2} . \mathrm{k}$

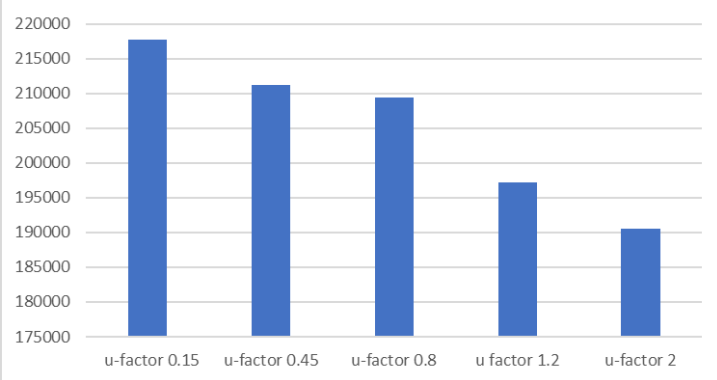

Figure 10 annual energy consumption on north façade with different $u$-factor

(source: researcher)

The result encourages designers to design north façade in MMB as a light skin with high $\mathrm{u}$ factor

\subsection{U-factor analysis of south façade}

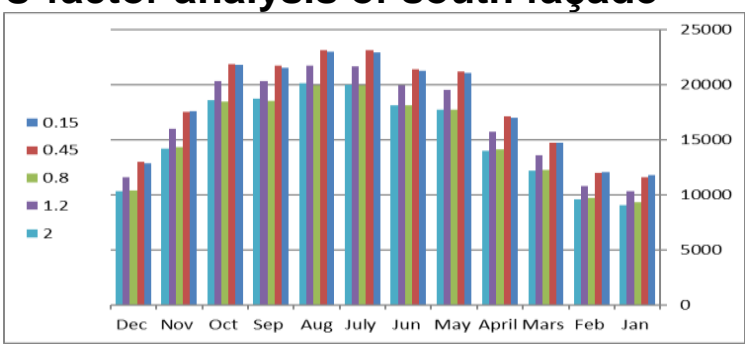

Figure 11 monthly energy consumption on south façade with different $u$-factor

(source: researcher)

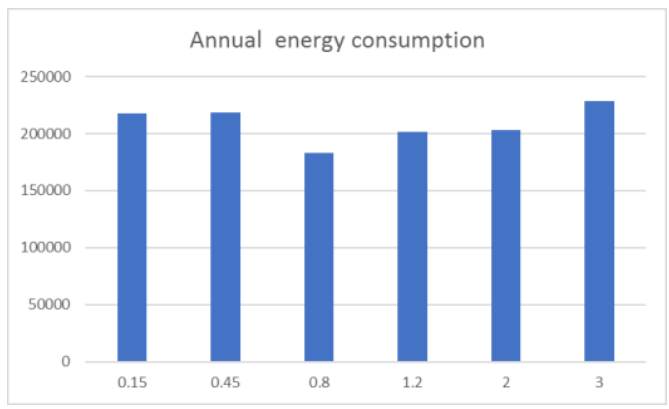

Figure 12 annual energy consumption on south façade with different u-factor

(source: researcher)

From the previous analysis, the research find that the south façade must be intermediate skin with nearly u-factor $0.8 \mathrm{w} / \mathrm{m}^{2} . \mathrm{k}$ as it is the min. energy consumption which again maximized the natural ventilation effect on building. From that we may predict that MMB properties is much nearer to passive buildings.

\subsection{WWR analysis of north façade}

By examine WWR on north façade in MMB in Cairo Egypt we find the results as following

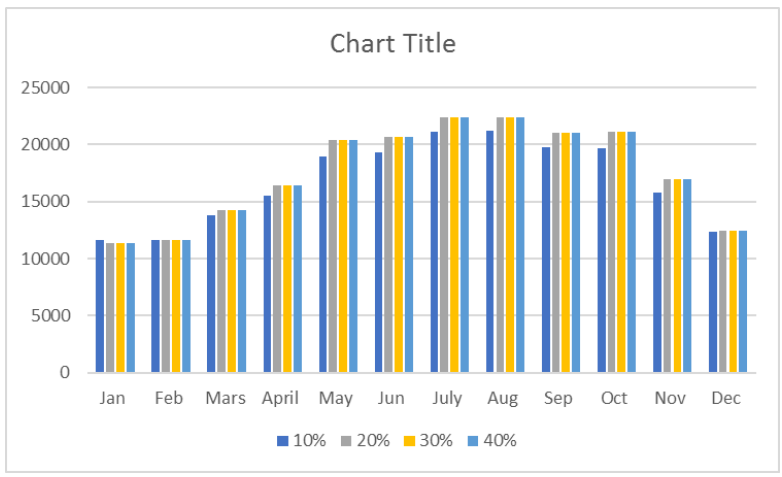

Figure 13 monthly energy consumption on north façade with different WWR

(source: researcher)

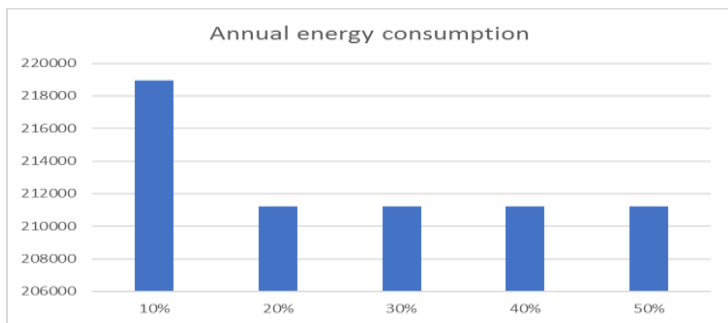

Figure 14 annually energy consumption on north façade with different WWR

(source: researcher) 
From the previous analysis, it is clear that the WWR doesn't harm building energy consumption in north except when the percent decrease to harm natural lighting with WWR $10 \%$ which makes the north façade a light skin.

\subsection{WWR analysis of south façade}

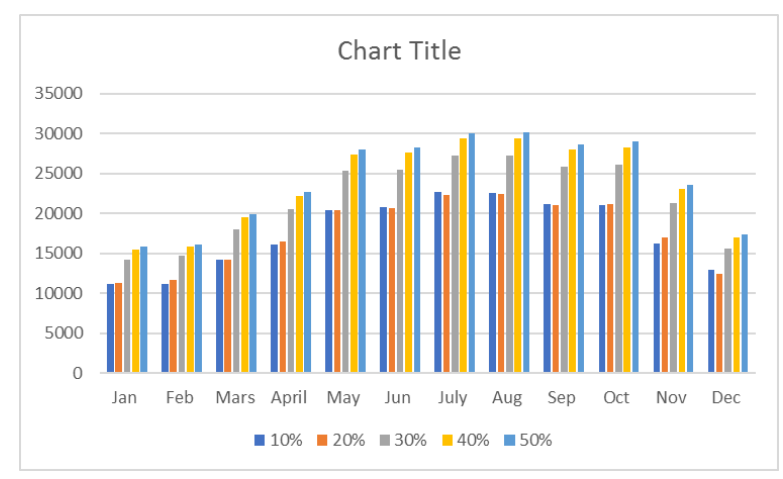

Figure 15 monthly energy consumption on south façade with different WWR

(source: researcher)

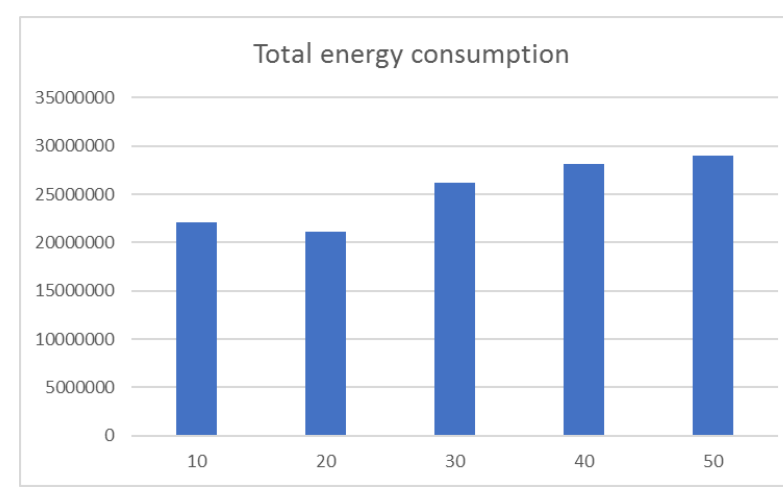

Figure 16 annually energy consumption on south façade with different WWR

(source: researcher)

From the previous research, it is clear that the south façade meet the WWR of $20 \%$ as the best energy consumption which differs from the Egyptian code of the south façade in Cairo which is $30 \%$ for ventilated buildings.

\section{CONCLUSIONS}

In this work series of computer simulations of different building envelope of MMB in cairo egypt . the research reaches different cconclusions

1- The MMB approch in egypt differ from the international approch of MMB as the egyption approch adative manually to outdoor temperature which make the architect must design office buildings with a pre-designed schedule and design
MMB envelope to reach the optimum energy consumption.

2- The MMB in Egypt near to treated as passive building with with south hivier envelope

3- The north façade in MMB in cairo is a light skin which doesn't harm energy consumption which its $\mathrm{u}$-factor may reach $2 \mathrm{w} / \mathrm{m}^{2} . \mathrm{k}$ and $50 \% \mathrm{WWR}$

4- The south façade still a more heavier skin which its U-factor lays around $0.8 \mathrm{w} / \mathrm{m}^{2} . \mathrm{k}$ and its WWR $20 \%$ as a more hiver skin than natural ventilated building in Egyptian code.

\section{REFERENCES}

1. http://www.cbe.berkeley.edu/mixedmode/about mm.html,1-1-2016, University of California

2. Olgyay, V., 1963, Design with Climate, Bioclimatic Approach and Architectural Regonalism, New Jersey: Princeton University Press.

3. Marqus and Morris, building, climate and energy, vol.1, p100, 1960.

4. Givoni, B., 1992. Comfort, climate analysis and building design guidelines. Energy and Buildings, Vol. 18(1), pp. 11-23.

5. ANSI/ASHRAE Standard 55, Thermal Environmental Conditions for Human Occupancy, 2010

6. Olgyay, V., 1963, Design with Climate, Bioclimatic Approach and Architectural Regonalism, New Jersey: Princeton University Press.

7. Marqus and Morris, building, climate and energy, vol.1, p100, 1960.

8. Givoni, B., 1992. Comfort, climate analysis and building design guidelines. Energy and Buildings, Vol. 18(1), pp. 11-23.

9. ANSI/ASHRAE Standard 55, Thermal Environmental Conditions for Human Occupancy, 2010

10. Berkeley university of California,CBE Indoor Environmental Quality, 2012

11. Givoni, B., 1992. Comfort, climate analysis and building design guidelines. Energy and Buildings, Vol. 18(1), pp. 11-23.

12. Fergus Nicol, Adaptive thermal comfort standards in the hot-humid tropics, Energy and buildings 36, pp. 628-637, 2004.

13. ${ }^{1}$ De Dear, R.J., \& Brager, G.S. (2002). Thermal comfort in naturally ventilated buildings: revisions to ASHRAE Standard 55. Energy and Buildings

14. 1 A Method for more specific Simulation of Operative Temperature in Thermal Analysis Programmes, Jørgen E. Christensen, Associate Professor, Department of Civil Engineering, Technical University of Denmark, 2008 
15. https://www.scribd.com/document/234929751/ 70

16. Climate, Comfort, \& Natural Ventilation: A new adaptive comfort standard for ASHRAE Standard 55 G. S. Brager* R. de Dear† Moving Thermal Comfort Standards into the 21st Century, Page 5 Oxford Brookes University, Windsor, UK, April 2001.

17. ANSI/ASHRAE Addendum $b$ to ANSI/ASHRAE Standard 55-2013

18. http://www.readbag.com/osr-ashrae-publicreview-draft-standards-lib-add-55-2004-d-ppr1draft-chair-approved

19. ASHRAE, ANSI/ASHRAE Standard 55R, 'Thermal Environmental Conditions for Human Occupancy', Atlanta, American Society of Heating, Refrigerating and Air-Conditioning Engineers, Inc. 2004.

20. J. Khedari, N. Yamtraipat, N. Pratintong and J. Hirunlabh, 'Thailand Ventilation Comfort Chart', Energy and Buildings, Vol. 32, N³, pp. $245-249,2000$

21. https://pt.scribd.com/document/315651481/895 0P219-sample-pdf

22. Nicol, F. (2004). Adaptive thermal comfort standards in the hot-humid tropics. Energy and Buildings 